This final bleached product yields all its colour on shaking with benzine containing 1 per cent ethanol. The benzine extract, brought back into neutral aqueous digitonin solution, possesses a spectrum-like curve e. It changes in colour with $p \mathrm{H}$, as does the whole bleached residue. It appears to be the same pigment as is extracted from bleached (russet) retinas (extract $B$ in the table above).

If curve $e$ is subtracted from $a$, a function roughly symmetrical about a maximum at $540 \mathrm{~m} \mu$ is obtained, similar to that observed by Köttgen and Abelsdorff ${ }^{1}$. Below $455 \mathrm{~m} \mu$ this function assumes negative values. Obviously it does not, as commonly supposed, represent the spectrum of porphyropsin itself.

In every detail so far examined, the porphyropsin system faithfully reproduces the behaviour of the rhodopsin system, but with quite different com. ponents. It appears to consist in a retinal cycle of light

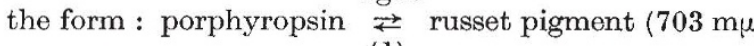
(1)

chromogen $+\ldots$. ) $\rightarrow$ yellow pigment (696 mu chro(2)

mogen $+\ldots.) \rightarrow$ porphyropsin. Isolation of the (3)

retina from the eye cuts the cycle at (3); extraction of porphyropsin from the retina eliminates in addition reactions (1) and (2).

It is curious that the possession of porphyropsin divides all freshwater fishes so far examined-eleven species in all-even from certain very closely related marine forms ${ }^{2,3}$. The division may not be absolute, for recently a number of marine fish visual purples have been reported to possess intermediate properties $^{6}$. These are possibly mixtures of rhodopsin and porphyropsin. The coincidence in a single retina of a number of visual systems accurately parallel in behaviour but differing in spectral properties should serve as an appropriate basis for colour vision.

Biological Laboratories, George WaLd.

Harvard University,

Cambridge, Massachusetts. March 31.

${ }^{1}$ Köttgen, E., and Abelsdorff, G., Z. Psych. u. Physiol. Sinnesorg. 12, 161 (1896).

"Wald, G., NATURE, [139, 587 (1937) ].

${ }^{3}$ Wald, G., Nature, 136, 913 (1935) : J. Gen. Physiol., 20, 45 (1936$37)$.

'Wald, G., J. Gen. Physiol., 19, 351, 781 (1935-36).

5 Ewald, A., and Kühne, W., Unters. physiol. Inst. Heidelberg, 1. 181 (1878).

${ }^{6}$ Bayliss, L. E., Lythgoe, R. J., and Tansley, K., Proc. Roy. Soc., B, 120, 95 (1936).

\section{Thermal Decomposition of Ethylene Oxide}

IN a series of papers communicated to the Faraday Society, an attempt has been made to prove that the thermal decomposition of a number of simple organic compounds may be accounted for on the assumption of the following mechanism.

The compound $A$ first undergoes change in accordance with an equation,

$$
A=B(+C) \text {. }
$$

This process, which is called the background reaction, is readily reversible when $A$ and $B$ represent ethane and ethylene, propane and propylene, and probably acetaldehyde and vinyl alcohol, but in the case which we are considering it is sensibly irreversible.
The main reaction, following on the background reaction, is represented by the equation,

$$
A+B=A B=(A B)=C+D \text {, etc. }
$$

where $A B$ and $(A B)$ represent the activated complex, and what has been termed an unstable intermediate. The latter may decompose, or even react with some other substance such as hydrogen, to form one or more products, but it is the rate of formation of the unstable intermediate which we measure.

Further study of the thermal decomposition of ethylene oxide furnishes confirmation of this theory. This compound decomposes in the neighbourhood of $400^{\circ}$ according to the equation,

$$
\left(\mathrm{CH}_{2}\right)_{2} \mathrm{O}=\mathrm{CH}_{4}+\mathrm{CO} \text {. }
$$

A little acetaldehyde is formed at the same time, and it has been suggested that this compound is an intermediate between ethylene oxide and the final products. However, it seemed likely, according to the theory referred to above, that the reaction,

$$
\left(\mathrm{CH}_{2}\right)_{2} \mathrm{O}=\mathrm{CH}_{3} \mathrm{CHO} \text {, }
$$

might really be the background reaction for the decomposition of ethylene oxide, in which case the main reaction would be initiated by the collision of molecules of ethylene oxide and acetaldehyde, represented by,

$$
\begin{aligned}
& \left(\mathrm{CH}_{2}\right)_{2} \mathrm{O}+\mathrm{CH}_{3} \mathrm{CHO}=\left[\left(\mathrm{CH}_{2}\right)_{2} \mathrm{O}, \mathrm{CH}_{3} \mathrm{CHO}\right]=2 \mathrm{CH}_{4} \\
& \quad+2 \mathrm{CO} . \\
& \quad \cdot \quad \cdot \quad \cdot \quad \cdot \quad \cdot \quad \cdot(5)
\end{aligned}
$$

To test this theory, quantities of ethylene oxide and acetaldehyde were heated separately in a silica tube for 30 minutes at $400^{\circ}$. In a third experiment the same quantities of ethylene oxide and acetal. dehyde was heated similarly, mixed together. As was anticipated, the quantity of carbon monoxide and methane obtained from the mixture was about ten times the sum of the quantities obtained in the experiments in which the two compounds were heated separately.

So far, it is only in the case of the hydrocarbons that it has been possible to eliminate the effect of the background reaction, and to study the main reaction by itself. However, by experimenting at temperatures at which ethylene oxide and acetaldehyde alone decompose very slowly, it is found to be possible to study in detail the process represented by equation (5).

This hypothesis enables us to dispense with the conception of the unimolecular reaction, and also of that of free radicals, in order to account for the thermal decomposition of simple organic compounds. The processes are accounted for on the supposition that the reactions involve simple bimolecular pro. cesses.

\section{Morris W. Travers.} C. G. Silcocks.

Department of Chemistry, University of Bristol, May 13.

\section{Inhibitions of Organic Decompositions by Nitric Oxide}

STAVELEY and Hinshelwood have recently shown that the thermal homogeneous decompositions of certain substances such as ethers and aldehydes are to a greater or less extent inhibited by small amounts of nitric oxide, and they have used this as a means of establishing the extent to which these reactions 